\title{
Aísthesis en la expresión
}

\section{Carlos Alberto Vargas Pacheco}

\author{
La expresión ha de considerarse \\ en su totalidad. \\ E. Nicol
}

\section{Introducción}

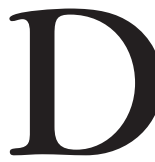

e acuerdo con el pensamiento de Eduardo Nicol, la nota característica del hombre es su expresividad. Esto no quiere decir que al ser humano lo distinga su capacidad de expresarse, en el sentido de generar expresiones determinadas a voluntad, sino que su simple presencia hace patente su ser: el hombre es expresión.

¿Qué expresa el hombre? Expresa su forma de ser humana, que comparte con otros hombres, y su modo individual de existir. Pero en el momento mismo en que ello ocurre hace expreso al ser. Ahora bien, el hombre comprende de inmediato lo evidente que es el ser, pues éste no se encuentra detrás de algo, "más allá" u oculto. El ser siempre está aquí y ahora, es presencia clara. El hombre capta y transmite esa evidencia; más aún, sólo bajo la certeza de que hay ser, el ser de la expresión (que en cada caso es el ser humano) se vincula efectivamente con lo otro. En efecto, no puede haber mayor confianza que el hecho "puro y simple" de que el ser se presenta en todos los entes.

No obstante lo anterior, gran parte de la tradición filosófica ha cuestionado y aun negado la evidencia del ser y, en general, no ha tocado el tema de la expresividad del hombre desde una perspectiva ontológica. Más todavía, la historia de la filosofía ha supuesto que aquello evidente, el fenómeno del ser, es contingente e incierto por el hecho de ser temporal. Puesto que la tradición -iniciada por Parménides, según afirma Nicol- ${ }^{1}$ escindió la unidad ser-devenir, todo lo relacionado con el cambio se volvió objeto de duda y de poca fidelidad. Mientras tanto, el ser se identificó (es decir, se tornó siempre idéntico) y se comprendió como aquello donde reside la verdad y cuya permanencia eterna se contrapone al devenir del mundo sensible. Así, de acuerdo con la tradición

\footnotetext{
${ }^{1}$ Cf. Eduardo Nicol, Metafísica de la expresión. México, FCE, 1974, p. 93.
} 
parmenídea, habría que superar el dato primario en pos de la realidad absoluta, de la verdad indubitable: el Ser. ${ }^{2}$ En el mismo tenor, una parte importante de la tradición -en especial las corrientes de estirpe platónica- relegó a lo más contingente todo el ámbito de lo sensible, precisamente por corresponder a lo más incierto. De modo que la escisión tuvo repercusiones, también, en la forma de comprender al hombre, pues dividir entre ser y devenir implicó de manera inmediata dividir entre la razón y lo sensible. Esto se debe a que la primera sería la facultad más adecuada para captar al Ser y lo segundo correspondería al devenir en virtud de que, a través de la sensibilidad, se capta el cambio o la contingencia.

Nicol advierte en su Metafísica de la expresión que, para superar la tradición que ha suprimido la importancia del devenir en el ser (y, por consiguiente, la expresión del hombre), habría que rescatar la experiencia primaria del ser, pues en ésta reside el fundamento claro de toda investigación posterior. Sin embargo, para llevar a cabo tal rescate, el filósofo catalán indica que hay que considerar tres puntos: el esclarecimiento de lo que se considera "percepción o intuición pura”, la consideración de la relación del ser y el conocer a través del "dispositivo atencional" y la revaloración del cuerpo. ${ }^{3} \mathrm{Si}$ bien el autor distingue estos tres aspectos para recuperar la experiencia primaria del ser, no los toma como momentos distintos, sino entremezclados. En suma, la captación del ser sólo es posible en virtud de que dichos aspectos se dan conjuntamente en el hombre al momento de la experiencia, no requieren la deliberación del individuo y operan indefectiblemente en cada caso. Así, la experimentación que acontece en cada hombre cuando se enfrenta con el mundo, no es un asunto trivial ni fácil de explicar. El fenómeno de la captación del ser que en cada hombre es natural, efectivo y cotidiano, es, en realidad, un proceso complejo que fue reducido a mera y simple sensación por gran parte de la tradición filosófica.

Desde la Grecia antigua, el ámbito de lo sensible quedó significado por el término aísthesis, que comúnmente se traduce por "percepción". Pero a lo largo de la historia, a dicho término se le fue reduciendo su sentido hasta que, en gran parte de la modernidad, se le concibió como "captación sensible". Las palabras "percepción", "intuición", "sensación" y otras semejantes señalan una parte específica del fenómeno complejo del sentir en general, por lo que cualquiera de dichos términos resulta limitado, pues indican sólo una operación

${ }^{2}$ Se coloca el término con mayúscula para referirse a la noción que se tenía del ser como lo absolutamente inmutable, imperecedero, eterno y perfecto, en gran parte de la tradición metafísica de la cultura occidental. A diferencia de dicha noción, se escribirá "ser" para referirse a la manera en que Nicol lo asume, a saber, como presencia inmediata y evidente.

${ }^{3}$ Cf. ibid., pp. 143-153. 
específica de todo el fenómeno perceptivo. Se ha optado por el término griego para los fines que se intentarán exponer en el presente texto, ${ }^{4} \mathrm{y}$ asimismo, se aventura la hipótesis de que la aísthesis influye fundamentalmente en los aspectos que Nicol ha señalado para la recuperación (y revaloración) de la experiencia primaria del ser. De este modo, se puede afirmar, con el aval de tesis concretas de Nicol, que la vuelta a la evidencia que supera la división llevada a cabo por gran parte de la tradición, supone la revaloración de lo estético en sentido radical, como aísthesis, es decir, como lo relativo al ámbito del sentir en general. El hecho de que "hay ser" implica que la expresión no sólo es lógica, sino también estética. En el presente texto se pretende sentar las bases para afirmar que si la expresión sólo se ciñe al logos es incompleta y que lo que le falta es su complemento: la aísthesis.

\section{Aísthesis y estética}

Como se ha mencionado líneas arriba, para una gran parte de la tradición la aísthesis se consideró lo más contingente e incierto y, por ello mismo, lo que requería ser superado para lograr la certeza. Era la razón -en Parménides se observa claramente- la que conducía al hombre por el único camino transitable: el del Ser y el de la Verdad indubitable e inmutable. ${ }^{5}$ Platón, en su intento por conciliar aquellos mundos entre los cuales oscila el hombre, afirmó que lo primero que se tiene que superar para lograr la captación del bien en sí (y también de la verdad y la belleza) es lo sensible. Así lo dice en el Banquete:

[...] ésta es justamente la manera correcta de acercarse a las cosas del amor o de ser conducido por otro: empezando por las cosas bellas de aquí y sirviéndose de ellas como de peldaños ir ascendiendo continuamente, con base en aquella belleza, de uno solo a dos y de dos a todos los cuerpos bellos y de los cuerpos bellos a las bellas normas de conducta, y de las normas de conducta a los bellos conocimientos, y partiendo de éstos terminar en aquel conocimiento que es conocimiento no de otra cosa sino de aquella belleza absoluta, para que conozca al fin lo que es la Belleza en sí. ${ }^{6}$

${ }^{4}$ En este sentido, se interpreta aísthesis como el sentir en general, es decir, sin distinguir la sensación de los órganos de los sentidos de los sentimientos afectivos. Ambos comparten el hecho de que "se sienten" y, por esta razón, son un sentir. En el presente texto, ésta es la manera en la que se pretende emplear el término aísthesis.

${ }^{5}$ Cf. Parménides, Poema ontológico, fr. I (Sexto, Adv. Math., vII, 3 (versos 1-30); Simplicio, De caelo, 557, 25 y ss. (versos 28-32)). Citado en G. S. Kirk, J. E. Raven y M. Schofield, Los filósofos presocráticos. Madrid, Gredos, 2008, pp. 322-332.

${ }^{6}$ Platón, Banquete, 211c-d. Las cursivas son de este texto. 
Y en República insiste:

Me parece [habla Glaucón], con todo, que lo que te propones es dejar definido que la visión del ser y de lo inteligible que se adquiere por la ciencia de la dialéctica, es más clara que la que viene de las llamadas [artes], en las cuales las hipótesis toman el lugar de los principios. Es cierto que aquellos cuyo estudio son las [artes] perciben necesariamente sus objetos por el pensamiento y no por los sentidos, pero como su investigación no los lleva hasta el principio, ya que su punto de partida son las hipótesis, por eso te parece a ti que no tienen la inteligencia de esos objetos. ${ }^{7}$

Siglos más tarde, en los inicios de la modernidad, Descartes halló la certeza en aquello que no lo hubo traicionado: la razón. De acuerdo con el filósofo francés, por la res cogitans, o cosa pensante, se obtiene la certeza absoluta: la existencia garantizada por el pensamiento. Sin embargo, esta garantía deja sola a la razón consigo misma y genera un abismo entre ella y lo externo. Desde entonces, el imperio de la razón y del pensamiento orilló a lo sensible a ser superado; se le consideró la base del error o como aquello por lo cual se brindan datos a la razón para que ésta, a partir de aquéllos, pueda generar conocimiento. Lo sensible, cuando más, no era sino un medio para que la razón tuviera contenido y no tenía ningún valor epistémico per se. Lo estético -entendido como el ámbito del sentir en general- no podía considerarse fuente de verdad, pero sí de satisfacción. La valía de la sensibilidad tuvo que encontrar un ámbito que le fuera más adecuado.

Cuando Kant distinguió las estructuras de la razón, lo estético adquirió dos sentidos relacionados, pero distinguibles. Por un lado, lo estético fue considerado como el resultado de operaciones llevadas a cabo por la estructura $a$ priori de la razón que hace posible toda experiencia. Por otro lado, lo estético entendido en un sentido más particular, como un tipo de experiencia que se relaciona con el deleite de lo bello, lo hermoso, en suma, lo emotivo. A ese ámbito de lo estético, Kant lo denominó "juicio estético”. El juicio estético, según el filósofo prusiano, no puede generar conocimiento teórico ni ser objeto de la ciencia (y tampoco de la filosofía) porque se ciñe a una determinada sensibilidad que es enteramente individual y su objetivación no es la objetivación de la cosa en sí. Por ello, no es posible hacer ciencia del juicio estético. ${ }^{8}$

${ }^{7}$ Platón, República, 511c-e. Las cursivas son de este texto.

${ }^{8}$ De hecho, Kant indica que: "Pues aunque por sí solos [los juicios estéticos] no contribuyan en nada al conocimiento de las cosas, pertenecen, sin embargo, a la facultad de conocer y muestran una relación inmediata de esta facultad con el sentimiento de 
Ahora bien, el término estética fue acuñado por primera vez por Alexander Baumgarten para referirse a una experiencia particular: lo bello. ${ }^{9}$ Además, fue el primero en generar una reflexión sistemática o filosófica sobre ésta, y adoptó el mismo término: estética.$^{10}$ A hora bien, en tanto que lo estético se redujo a la experiencia calocéntrica, ${ }^{11}$ no podía considerarse un estudio científico que condujera a la verdad porque no se ciñe a las formas rígidas de la razón pura. En todo caso, la estética se halló alejada de la ciencia y se adhirió al arte. La verdad, de acuerdo con gran parte de la tradición, se consigue con la razón y trascendiendo todo tipo de sensaciones y emociones. La verdad sería, entonces, in-experimentable con la estética. ${ }^{12}$

A pesar de lo anterior, ciertas corrientes de la filosofía optaron por reconsiderar al arte como fuente de estudio y como posible vía de acceso a la verdad. Partiendo de esto, la estética (entendida como juicio estético) comenzó a tener un papel importante no sólo en los estudios filosóficos, sino en los sociológicos y psicológicos, ${ }^{13}$ entre otros, pues en ella se presentaban elementos que

placer o dolor, según algún principio a priori [...]" (Immanuel Kant, Crítica del juicio. Madrid, Tecnos, 2007, p. 75).

${ }^{9}$ Para ahondar en este punto, $c f$. Raymond Bayer, Historia de la estética. México, FCE, 1984, pp. 183-186.

${ }^{10} \mathrm{El}$ lector notará que se hacen distinciones cuando se habla de lo estético, la estética y Estética. Lo primero se refiere a todo el ámbito del sentir que caracteriza la experiencia humana en general. Para referirse a tal ámbito, se ha preferido emplear el término griego aísthesis en el presente texto (como se mencionó en la nota 4) aunque también se menciona como "lo estético", "el sentir" o "lo sensible". Por su parte, la estética indica un tipo de experiencia más particular, a saber, aquella que se refiere a lo bello y todo lo relacionado con la expresión artística; tiene más relación con lo que Kant denominó "juicio estético". La Estética sería la reflexión racional que estudia, específicamente, la experiencia estética, esto es, las expresiones y experiencias de lo bello y el arte; esta última acepción sería la heredada por Baumgarten. Como puede apreciarse, lo estético fundamenta y posibilita a la estética y a su consiguiente estudio sistemático y reflexivo. Por lo tanto, lo estético o aísthesis es un término más general que estética y también que Estética. Sobre el mismo punto $c f$. Josu Landa, "Ascética y estética", en Tanteos. México, Afínita, 2009, p. 158.

11 "Calocéntrico", de kalós: "belleza", en griego antiguo. Es decir, que el núcleo es la belleza. Acerca del mismo punto Josu Landa comenta que: "[...] lo cierto es que con el tiempo el significado de esa palabra se vio afectado por una restricción kalocéntrica -en virtud de la cual, la estética sería una teoría de lo bello- y por su reducción a una ciencia relativa al arte" (idem).

${ }^{12}$ Sin embargo, se puede aceptar que existe una cierta conexión entre la estética y la verdad, en virtud de que aquélla se vincula en algún modo con la realidad absoluta. No obstante, gran parte de la tradición puso en entredicho la relación de la estética con la verdad, porque no la fija, como el entendimiento.

13 Piénsese, por ejemplo, el caso de la Escuela de Fráncfort, donde pensadores como Adorno, Horkheimer y Fromm son ejemplos de la empresa por llevar a cabo dichos estudios. 
permitían entender al hombre de una manera más integral que lo que podían hacer estudios de carácter lógico-formales. ${ }^{14}$ No obstante, la peculiaridad de la estética consiste en la aceptación de una experiencia distinta de muchas otras (a saber, lo bello, lo sublime y, en general, todo lo que resulte de una relación con lo artístico) y no la reintegración del sentir en general, para alcanzar el conocimiento de lo verdadero. Dicho en otros términos, si la experiencia de lo bello o del arte abre una posibilidad para acceder a la verdad o al Ser, esto no implica que pueda accederse a aquello mediante la aísthesis, es decir, mediante todo lo que implica el sentir en general. En todo caso, la estética sería una experiencia más elaborada o depurada y, por tanto, "superior" a una mera percepción de algo dado.

Subyacen, por lo menos, dos prejuicios en la base de esta última idea. El primero es que la experiencia de la estética implica un cierto tipo de reflexión e interpretación mayor al de cualquier otra; por tanto, la experiencia estética conlleva una racionalidad "judicativa" que la mera sensación no requiere. El segundo prejuicio, derivado del anterior, es que hay meras experiencias que no son trascendentes, sino hasta que adquieren sentido por medio de la razón. Puesto que la estética ya está dotada de sentido, porque conduce a una reflexión particular - a saber, lo artístico o lo bello-, es claro que no puede ser considerada sólo como una simple experiencia primaria.

Ahora bien, cuando Nicol señala el primer punto para la reivindicación de la experiencia originaria del ser, indica que: "[...] la idea misma de una pura percepción sensible es una idea abstracta, porque el entendimiento está presente y activo ya en la experiencia perceptiva. La [aísthesis] implica al [nous], y no consiste en la pura percepción de unos órganos sensoriales". ${ }^{15}$

Uno de los errores de gran parte de la tradición ha sido la escisión entre lo sensible y lo inteligible. Desde esta perspectiva se ha de considerar que lo estético no puede ser superado ni es el mero punto de partida del conocimiento. Frente a esto, se puede afirmar que en la experiencia cotidiana parece inaccesible lo que se ha llamado "percepción o sensibilidad pura", pues cada experiencia - por "simple" que sea- es ya una configuración compleja que se presenta en el hombre. La conciencia de una experiencia es ya, como afirma Nicol, la inter-acción del entendimiento con el sentir. Cuando se representa una "impresión simple" (como quería Hume), ello supone la presencia del logos para hacerlo inteligible. Por consiguiente, no existe una manera de acceder a la

${ }_{14}^{14}$ Tales estudios pretendían reducir la mayor parte de los problemas a la formalidad lógica del lenguaje, pues asumían que todo lo humano (o más bien, la mente humana) podía ser reducido a proposiciones con validez o invalidez lógica. De este modo, análisis de este tipo hacían problemática una comprensión cabal del hombre, precisamente porque dejaban de lado cuestiones inherentes a su ser: la expresión, por ejemplo.

${ }^{15}$ E. Nicol, op. cit., p. 143. 
"sensibilidad pura", a esa afección que no tiene absolutamente nada de racional. Revalorar lo estético, en consonancia con lo anterior, no es hacer hincapié en que los datos de los sentidos o la emotividad, independientes de la razón, son la fuente primera del conocimiento. Lo estético implica la asunción del hombre en su plena complejidad, pues, como se ha señalado, todo el sentir, o sea, la sensación, percepción, intuición, emoción y demás aspectos semejantes suponen el componente racional que los hace inteligibles: lo lógico - es decir, lo concerniente al logos y, en ese sentido, lo racional-supone lo estético.

Ser hombre quiere decir ser lógico-estético. El ser humano determina su vida, es decir, elige y ejerce su libertad no sólo por medio de la razón. La existencia se configura a través de múltiples estímulos y cada uno de ellos es, al mismo tiempo, lógico y estético. No existe en la vida de los hombres una experiencia que sea puramente racional o puramente sensible, toda experiencia es una conjunción de ambas. En este tenor, resulta claro que la expresión del hombre no se reduce a su facultad racional. La vida humana, que es donde se da la expresión del hombre, está motivada por la interacción del logos con la aísthesis. Pensar no basta para vivir, por esto el ser de la expresión no puede ser sólo lógico: su sentir también es expresivo.

En síntesis, se puede afirmar que la aísthesis o lo estético ya no puede considerarse como dependiente o separado radicalmente de la razón. La racionalidad se encuentra siempre presente en todo lo estético y, por tanto, esto último no se refiere a "una parte" del ser humano. La reivindicación de lo estético es el punto que permite comprender al ser humano en su complejidad. Por otro lado, lo que en estos tiempos se entiende por "estética" no se refiere a todo el sentir, sino a una determinada experiencia; pero ello no obsta para que la aísthesis sea su fundamento, pues el sentir se adhiere a lo bello de una manera muy peculiar. Lo estético posibilita la captación del ser en su presente y evidente manifestación. El ser es estético para el hombre porque es en lo estético donde se hace presente el ser.

\section{Fenómeno y aísthesis: Kant}

Es bien conocida la revolución que el filósofo prusiano llevó a cabo en la "ciencia primera". Inmerso en la tradición que ha sostenido que el Ser está más allá de lo que puede percibirse a simple vista, Kant estableció los límites que la razón posee para articular todo conocimiento posible. Así, esclareció la estructura que permite el conocimiento para la ciencia al tiempo que ubicó, de una vez por todas, el lugar que le corresponde a la metafísica.

Kant fue muy consciente de que el objeto de estudio de la metafísica -es decir, los primeros principios- se encuentra alejado de la experiencia inme- 
diata. Los principios son producto de la razón y su imposibilidad de contrastarlos con la experiencia es lo que hace nulo el progreso en tal indagación. Por el contrario, las ciencias que repercuten en el terreno empírico gozan de un avance notable y fructífero; en efecto, el conocimiento teórico -según denominó Kant al conocimiento de las ciencias- es aquel que procede de los fenómenos. Éstos son susceptibles de ser experimentados, pues no se puede tener un conocimiento científico que no proceda de la experiencia, esto es, de la objetivación que lleva a cabo la razón a través de su estructura a priori. Si la razón permite la configuración de los fenómenos, entonces es posible hacer ciencia de ellos, porque se produce la experiencia efectiva y la posibilidad de llevar a cabo el estudio teórico sobre ella. Puesto que, como afirma Kant, ${ }^{16}$ la metafísica tiene como objeto de estudio los principios supra-sensibles, es claro que no son experimentables y, por tanto, es imposible el conocimiento teórico de ellos. ${ }^{17}$ La ciencia, en todo caso, se basa en fenómenos, esto es, en lo que aparece. Si la metafísica sostiene que su objeto de estudio se encuentra allende los límites de la experiencia, entonces no es fenoménica. Por tanto, la metafísica no puede ser ciencia empírica.

Los fenómenos implican lo estético en sentido radical, porque la experiencia requiere necesariamente el sentir para acontecer. Si alguna experiencia no cumple con esto, entonces no es fenoménica y, por tanto, es imposible que se haga ciencia de ello: la metafísica, en consonancia con el pensamiento kantiano, es nouménica. Aunque lo fenoménico sea estético, hay que enfatizar el peso que la razón tiene en ello. En efecto, lo estético no se refiere con exclusividad a las "sensaciones puras"; la aísthesis es más que mera aprehensión sensible. Ahora bien, según Kant, la estructura de la razón es la que hace posible que se tenga percepción; desde este punto de vista, la forma racional es la que condiciona lo estético y ello hace imposible que se tenga acceso a las "sensaciones puras”, pues toda sensación ya está determinada por la razón. Por otro lado, bajo el sistema kantiano, el sentir es susceptible de ser puesto a un lado para acceder a la forma o estructura de la razón, al modo en que se puede vaciar de su contenido a un envase. Por ello, Kant puede analizar a la razón pura, libre de contenidos, mientras que la aísthesis se halla siempre determinada o

${ }^{16}$ I. Kant, Los progresos de la metafísica. México, UAM/UNAM/FCE, 2008, p. 28; donde afirma el filósofo: "De aquí se sigue el principio de la división de toda metafísica: no es posible, por lo que concierne a la facultad especulativa de la razón, ningún conocimiento de lo suprasensible (noumenorum non datur scientia)".

${ }^{17}$ Recuérdese que, de acuerdo con Kant, el conocimiento teórico es aquel que proviene de la experiencia que, a su vez, es posible por la estructura a priori de la razón. Puesto que los primeros principios no provienen de una experiencia y, entonces, no "caen" dentro de la estructura de la razón, no es posible hacer ciencia de ellos, es decir, tener conocimiento teórico. 
condicionada por la razón, de ahí que sea impensable su "pureza", pues ésta es, literalmente, irracional. Dicho en otros términos, lo estético sólo puede ser tal porque la razón lo ordena de esa manera. Como se puede observar, desde la perspectiva kantiana, lo estético no tiene relevancia por sí mismo, sino en tanto que es la materia que la estructura racional moldea. Esta última es la que amerita mayor importancia en tanto que ordenadora de lo sensible. Incluso el "juicio estético" también se considera como una estructura de la razón (aunque diferente de la estructura del entendimiento, que procura la representación fenoménica u objetiva), pese a que no genere conocimiento teórico. ${ }^{18}$ En el fondo, el "gran sistema de la experiencia" como lo denominó el propio Kant, sólo es posible por la estructura de la razón.

Como bien apunta Nicol, Kant intentó superar la tradición que había extirpado al Ser de la experiencia primaria. Así, para el filósofo prusiano lo esencial de las cosas, o bien su "ser en sí" o noúmeno, no podía ser re-presentado por la razón, pues todo lo que se manifiesta, o sea, los fenómenos, tiene que pasar necesariamente por la percepción sensible. De hecho, Kant afirma en la Crítica de la razón pura que:

Sean cuales sean el modo o los medios con que un conocimiento se refiere a los objetos, la intuición es el modo por medio del cual el conocimiento se refiere inmediatamente a dichos objetos [...]. Tal intuición únicamente tiene lugar en la medida en que el objeto nos es dado [...] La capacidad (receptividad) de recibir representaciones, al ser afectados por los objetos se llama sensibilidad. Los objetos nos vienen, pues, dados mediante la sensibilidad y ella es la única que nos suministra intuiciones.

El objeto indeterminado de una intuición empírica recibe el nombre de fenómeno. ${ }^{19}$

La intuición es el conglomerado de sensaciones ordenadas por la estructura llamada "intuición pura" que, a su vez, está conformada por el tiempo y el espacio como "formas puras de la sensibilidad". ${ }^{20}$ En suma, toda sensación será estructurada por la forma pura de la intuición y las categorías de la lógica para con-formar el conocimiento. Sin embargo, habrá que cuestionar si la supuesta pureza es efectiva de hecho. En efecto, aquí se encuentra una paradoja en el propio planteamiento de Kant, pues el acceso a la forma pura de la razón supone que ello mismo es una experiencia posible en el hombre. Pero dado que la razón pura está vacía de contenido y todo lo sensible es contenido de

${ }^{18}$ Cf. I. Kant, Crítica del juicio, pp. 101-105.

${ }^{19}$ I. Kant, Crítica de la razón pura. Madrid, Alfaguara, 2004, pp. 65-66.

${ }^{20}$ Cf. ibid., p. 66. 
la razón, es claro que no puede haber experiencia de ésta: la razón depurada sería, entonces, in-experimentable.

Nicol concede que Kant procede con toda legitimidad al tratar de superar la tradición y, a pesar de eso, yerra cuando afirma que la "cosa en sí" no puede representarse. Para el filósofo catalán, Kant sigue asumiendo que lo "en sí" es aquello que ya desde Parménides y Platón es accesible, únicamente, con la razón y sin incumbencia de lo sensible. ${ }^{21}$ Desde luego, el aparecer del ente -el fenómeno- no hace patente lo esencial ni muestra aquello que hace que el ente sea sí mismo. Por ello, Kant, asumiendo esta herencia de gran parte de la tradición, niega el camino de lo nouménico en tanto que no se puede experimentar y, por ende, tampoco puede haber conocimiento teórico de ello. Tomando en cuenta lo anterior, cuando Kant lleva a cabo el análisis que muestra la estructura trascendental de la razón, afirma que sólo puede haber fenómenos si hay objetos que estimulen la sensación; ésta, a su vez, adquiere sentido merced a la intuición pura y a los conceptos puros del entendimiento. Dicho en otros términos, sólo se puede hablar con propiedad de fenómenos cuando los objetos estimulan sensitivamente al hombre y ello, según se puede apreciar en la evidencia cotidiana, sólo sucede en el plano óntico, pues son los entes objetivados por la razón, los que "estimulan" al ente expresivo (activan el dispositivo atencional, para decirlo con Nicol). No obstante, Kant aún mantiene una noción de sensación como algo separado de la racionalidad. Según él, son las sensaciones las que captan los estímulos de los objetos y a partir de aquéllas se activa el entendimiento. El filósofo de Königsberg no niega la existencia de las puras sensaciones, pero éstas no parecen representables sin racionalidad; esto implica que la sensación "en sí" podría considerarse como otra modalidad del noúmeno y, por tanto, inaccesible fenoménicamente al hombre. Por consiguiente, la sensibilidad, aunque distinguible de la razón, no puede presentarse más que ordenada por esta última. Ya en Kant, pues, la experiencia es razón que, por el sentir, objetiva los entes y éstos, a su vez, se dejan intuir por el ser humano. Por ello, sólo se puede hacer ciencia de los entes.

Pero el ser no es un ente. Nicol ha advertido casi al inicio de su Metafísica que la diferencia ontológica es rigurosamente necesaria ${ }^{22}$ y evidente. El ser se "capta" en el ente, pero no es uno de ellos ni la suma de todos. Ahora bien, si la estructura que plantea Kant es adecuada, se ha de afirmar que lo óntico es lo único fenoménico y no el ser, precisamente, porque no es un ente. Por tanto, siguiendo el esquematismo kantiano, podría señalársele a Nicol que el ser no puede ser fenómeno strictu sensu porque no surge a partir de una sensación ni intuición, sino a partir de una abstracción que proviene de los entes. Dicho

${ }^{21} C f$. E. Nicol, op. cit., pp. 113-114.

${ }^{22}$ Cf. ibid., p. 23. 
en otros términos, primero habría visión fenoménica de los entes y, a partir de ésta, la comprensión de que su "estar allí" es el ser. Como puede apreciarse, esto iría en contra de lo que Nicol ha señalado, es decir, que en la captación de los entes se da, en el mismo instante, la mostración y captación del ser. Pero, entonces, ¿cómo puede ser fenómeno el ser si no es sensible? ¿Cómo es que se ve el ser si lo que se percibe son objetos concretos?

Nicol concedería que el fenómeno es todo aquello que se presenta ante el hombre, en tanto que es un aparecer. Desde luego, el fenómeno kantiano supone que la cosa en sí se halla presente pero amorfa e incognoscible, por ello, la razón "vuelve a presentarla" (esto es, la re-presenta) de forma cognoscible al sujeto. En otras palabras, el ser de lo re-presentado por el fenómeno es una presencia que requiere la mediación de las formas puras de la razón; por tanto, el ser "en sí" no puede ser captado fenoménicamente. El catalán no negaría esta condición que impone el sistema kantiano. Sin embargo, la respuesta que ofrece Nicol consiste en afirmar que la representación objetiva del fenómeno kantiano es ya una manera de la presencia del ser. Es decir, el hecho de que la razón condicione lo "en sí" para tornarlo un aparecer ante ella no mengua el hecho "puro y simple" de que aquello representado es. La re-presentación del fenómeno kantiano es, en todo caso, presencia del ser. Por consiguiente, si el fenómeno en Kant se constituye a partir de la intuición y el entendimiento, esto es, lo estético y lo lógico, resulta entonces que el ser como fenómeno se capta de la misma manera porque se hace presente en el momento mismo de la objetivación. Con base en esto, se puede afirmar que todo objeto fenoménico, en tanto que es una presencia, revela en ello mismo al ser; por esto el ser se muestra siempre, el ser es fenómeno.

Si se retoma la consideración que Nicol enuncia referente a la aísthesis, se llegará a la conclusión de que el fenómeno no es pura percepción sensible ni pura razón. El acontecimiento de los entes, su "fenomenicidad", no se capta primero mediante lo sensible para después ser ordenado por principios que operan en la razón. O bien, si ello fuera cierto, no es posible mirar por separado en la propia experiencia la manera en la cual la razón, por sí misma, ordena las sensaciones; en la cotidianidad ese procedimiento es unitario y opera indefectiblemente en cada situación vital. El análisis kantiano sirve para tratar de discernir los elementos del proceso de un hecho que todo el tiempo le sucede al hombre: captar fenómenos. Sin embargo, es imposible mirar de facto a la razón pura o las sensaciones independientes de la racionalidad en la vida cotidiana. Si hay fenómenos, se debe a que éstos son sensibles y racionales a la vez. Dado que, de acuerdo con Nicol, el ser es un fenómeno, entonces se capta estética y lógicamente.

Lo anterior, sin embargo, puede generar la confusión de que el ser es un fenómeno del mismo modo que otros. Lo común entre el ser y los entes es que 
son captados estética y lógicamente y por ello son fenómenos. Pero el quid de la diferencia de esos dos términos ligados por dicho punto en común, consiste en que el ser, de acuerdo con Nicol, es el fenómeno primario. En efecto, al captar un ente se "ve" intrínsecamente el ser. Al percibir cualquier ente se manifiesta, en ese mismo instante, su ser: la presencia del ente hace indudable que es. El ser, no obstante, no es el ente mismo porque cada uno posee una forma determinada (sea familiar al hombre o no) que no comparten todos. Pero el hecho de ser no es algo exclusivo de tal o cual ente sino que es común a todo lo que es: el ser no es parte de los entes aunque esté en cada uno de ellos. Si el ser es primario, se debe a que es reconocible de inmediato porque se halla en la diversidad entitativa: lo que se reconoce inmediatamente en el acontecimiento del ente es que es, aunque se ignore lo que sea exactamente dicho ente. Puesto que el ser se nota en los entes y éstos, a su vez, sólo son captables como fenómenos, resulta evidente que el ser también es fenómeno. Pero no sólo eso, dado que el ser es común a todos los entes, queda claro que no es un fenómeno contingente; los entes pueden aparecer y desaparecer, pero el ser - de acuerdo con Nicol- no. Por lo tanto, lo común entre el ser y el ente es que son fenómenos, pero la diferencia es que el ser es el único fenómeno permanente porque siempre es presencia, mientras que los entes son fenómenos contingentes. ${ }^{23}$ Por otro lado, si como se mencionó líneas arriba, todo fenómeno implica aísthesis y ésta es imposible sin el logos, resulta que el ser es siempre estético y lógico, al mismo tiempo.

\section{Aísthesis como símbolo del logos}

En el hombre la expresión es lógica. Efectivamente, la palabra y el pensamiento vinculan a un individuo con otro en el acto comunicativo. Ser lógico es ser dialógico, o sea, simbólico. Se debe recordar el peso o la importancia preeminente que posee la noción de "símbolo" para Nicol, entendido en su sentido radical, es decir, como la re-unión de dos fragmentos separados pero afines. De acuerdo con el filósofo catalán, siguiendo a Platón en el Banquete, el hombre es símbolo del hombre. En este sentido, cada ser humano es un fragmento segmentado de un prójimo y su afinidad ontológica es reconocible a simple vista; con base en esto, el acto comunicativo - que requiere logos- es la evidencia clara de la vinculación o re-unión entre los hombres. Por esto, toda expresión es simbólica y fenoménica a un mismo tiempo. Esto último se debe a

\footnotetext{
${ }^{23}$ Quedan, sin embargo, abiertas las siguientes cuestiones: si los entes son contingentes, entonces podría pensarse que dejará de existir toda entidad; ¿sería posible, entonces, que el ser fuese fenómeno? ¿Puede el ser manifestarse sin entes, es decir, en nada?
} 
que, por un lado, la expresión requiere ser expuesta a otro hombre porque, en sí misma, es incompleta y necesita un "ante quien" para completarse, incluso en el pensamiento individual. ${ }^{24}$ Por otro lado, el otro reconoce su afinidad ontológica con aquel que expresa y, como lo expresado es manifiesto, esto es, fenoménico, se re-unen los interlocutores en el acto comunicativo. Ahora bien, esta manifestación, al ser una experiencia, no puede sino ser captada a través de los sentidos que, en el instante mismo en que perciben, suscitan en el receptor una interpretación. Pero no es la interpretación misma la que permite que un hombre reconozca al otro; por el contrario, el ejercicio hermenéutico es posible porque los interlocutores se han identificado fáctica y vivencialmente, pues se percatan, sin temor a equivocarse, de que el otro es un semejante. Literalmente, ante otro hombre, el individuo se siente identificado; esta sensación de identificación es ya una identificación dia-lógica, porque en el sentir se encuentra ya integrado el logos.

La manifestación del fenómeno expresivo no es un asunto que dependa de la razón exclusivamente. Reconocer al otro, aunque sea simplemente por su presencia, revela un ejercicio complejo en uno mismo. El reconocimiento implica toda una gama de elementos que advierte la imposibilidad de reducirse a pura racionalidad: mirar al otro supone la estimulación sensible, una cierta actitud frente a él y una interpretación; en suma, la expresión es un fenómeno que involucra todo lo estético, el sentir en general. Si la aísthesis engloba lo enunciado y se presenta en el fenómeno expresivo, que es simbólico, puede concluirse que la relación simbólica es también estética. Lo estético de una expresión requiere al otro para sentirse en comunidad: la expresión es lo sentido común del hombre.

En diversos pasajes de la Metafísica y en la Crítica de la razón simbólica ${ }^{25}$ Nicol enfatiza el papel preponderante del logos en la expresión: el ser de la expresión es tal porque es locuaz e intelectivo. ${ }^{26} \mathrm{El}$ logos es vínculo con el ser y con el otro, pues a pesar de que el ser es fenómeno, éste se presenta, o sea, se ex-pone ante el otro mediante la palabra. Pero, además, si el fenómeno es

${ }^{24}$ Recuérdese que incluso en el pensamiento se genera en el individuo una suerte de desdoblamiento, tal como lo advierte Platón cuando afirma que "el pensamiento es el diálogo interno y silencioso que lleva a cabo el alma consigo misma" (cf. Platón, Teeteto, 189e y Sofista, 263e).

${ }^{25}$ Cf. E. Nicol, Crítica de la razón simbólica. México, FCE, 1982, pp. 233-255.

${ }^{26}$ Con "intelectivo" quiere indicarse, por un lado, que el hombre es capaz de emplear su inteligencia para captar lo racional de la realidad y la inteligencia de otro hombre y, por otro, la capacidad de proyectar en lo no-inteligente su inteligencia (además, se está empleando inteligente como sinónimo de "racional", porque no se intenta esclarecer las facultades mentales del hombre, sino que se están tomando como todo el ámbito de lo lógico). 
en parte racional, entonces el ser es lógico porque se comprende o entiende en el momento mismo que se le mira, pues las puras funciones físicas que son estimuladas por el exterior, sin la presencia lógica, carecen de sentido y, propiamente, de presencia: no se puede dar cuenta de lo que es, más allá del logos; por esto, el ser es fenómeno. La nota peculiar del logos es que se dirige a un semejante, a un otro-yo y, en ese mismo instante, este hecho re-presenta (es decir, muestra de nueva cuenta) ante el otro aquello de lo que se habla.

Pero el logos no puede ser puramente lógico, en el sentido de únicamente racional, pues como el propio Nicol ha afirmado:

La ambigüedad de tal idea del hombre [la idea del hombre como "animal racional"] no se resuelve mientras no quede a su vez definida esta propiedad del logos que se ha desprendido de las demás, con el fin de proponerla como esencialmente representativa. En el momento en que el griego concibe al hombre como ser del logos, ya está en vigor, aunque mal definida, una distinción entre la razón y la expresión verbal. ¿Cuál de los dos es efectivamente definitorio: el logos pensante o el logos expresivo? Incluso si el logos mantuviese todavía en la definición el significado de una capacidad expresiva, no sería este atributo suficientemente definitorio, porque excluiría las otras formas de expresión no verbales. Por el contrario, la identificación primaria del hombre como ser de la expresión define realmente al hombre, es decir, no sólo lógicamente: lo abarca de manera total porque, al reconocerlo por su forma de su ser que está patente, a la vez lo distingue de cualquier otra forma de ser. ${ }^{27}$

El logos posee una unidad compuesta que puede fracturarse: "Experiencia y razón pura, apariencia y esencia: al romperse la unidad del conocimiento y la unidad del ente, se rompe también la unidad del logos". ${ }^{28}$ Como puede apreciarse, el logos no es pura razón ni mera palabra. Existe una doble escisión: por un lado, entre la razón y la palabra porque el pensamiento -desde la Antigüedad- es más real que la emisión sonora de los términos ${ }^{29}$ y, en última instancia, las palabras sólo sirven de medios para referirse a la realidad. Por otro lado, hay una separación de las "otras formas de expresión no verbales"

${ }^{27}$ E. Nicol, Metafísica de la expresión, p. 137. Los resaltados son del presente texto (salvo el resaltado de la palabra "realmente").

${ }^{28}$ Ibid., p. 115.

${ }^{29}$ Piénsese, por ejemplo, en el Cratilo de Platón, en donde se elucida la idea de que las palabras obtienen su verdadero sentido cuando se adecuan cabalmente a las formas originales de las cuales proceden los términos. Podría decirse, entonces, que el logos humano es posible y, por tanto, posterior al logos eidético. 
respecto de la palabra y la razón como podría ser, por ejemplo, la expresión corporal que se manifiesta en el movimiento del otro, en la danza o plasmado en la escultura e incluso en una fotografía. Pero quizá se trata más de una distinción que de un hiato. En efecto, la apariencia de que el logos está más apegado a lo racional permite distinguirlo y aun separarlo del cuerpo, esa parte imperfecta y contingente donde encontraría su origen, precisamente, la expresión corporal. Sin embargo, la expresión corporal sería también lógica porque requiere razón para orientar, entender e interpretar el sentido de sus movimientos. Toda expresión corporal implica un ejercicio de interpretación que no sería posible con la ausencia del logos: interpretar es generar un sentido racionalmente. Como se ve, aun las expresiones no verbales suponen el componente racional (el sentido lógico del logos) que permite comprender al otro como ser común. El otro puede no emitir ni una sola palabra y, sin embargo, se le puede re-conocer su ser que está "a flor de piel". Esta piel es comprendida lógica y estéticamente a la vez, pues el logos no consigue, en sí mismo, el reconocimiento cabal de ese otro que se siente como uno mismo; requiere la aísthesis para sentir lo que le es afín al hombre: su símbolo. Que el hombre sea el símbolo del hombre es una cuestión vital, pues no basta entenderlo, es una cuestión que inevitablemente se siente, se percibe, se mira. La sensación de comunidad (esto es, de sentirse común al otro) se respalda y fortalece con la comprensión que el logos procura. La ruptura de esto se da sólo cuando, a pesar de sentirse común al otro, la razón se empeña en negar tal evidencia al dar razones de por qué lo que se percibe es falso. ${ }^{30}$

Por otro lado, toda comprensión racional es, al mismo tiempo, una experiencia que con-mociona al hombre. En efecto, el ejercicio intelectual podría considerarse ajeno al cuerpo. No obstante, es un hecho manifiesto en la vida cotidiana que hay sensaciones que no son ocasionadas por un ejercicio físico, aunque se extiende por todo el cuerpo; por ejemplo, después de una ardua labor racional, el hombre presenta una fatiga total, es decir, no sólo se ha fatigado su mente sino todo él: el cuerpo, en conjunto, reacciona con el logos,

${ }^{30}$ Un ejemplo claro de esto han sido, notablemente, todos los discursos racistas a lo largo de la historia. El convencimiento de que se es diferente al otro, a partir de razones aducidas por medio de inferencias o de supuestos de todo tipo de ideologías (religiosas, políticas, sociales, etcétera), ha derivado en la negación de la evidencia simbólica del hombre y la consiguiente justificación de imposición de unos sobre otros. Este punto bastaría para iniciar todo un análisis sobre la pérdida de visión de la "igualdad ontológica" del hombre, como crítica a diversas tesis antropológicas o sociológicas que asumen la guerra y la voluntad de dominio como un rasgo inseparable del ser humano. Desafortunadamente, dada la temática del presente texto, no se podrá seguir explorando este punto, aunque no se quiso dejar pasar de largo la importancia que puede tener, a partir de las bases que Nicol ha ofrecido. 
no es ajeno, se involucra. Ciertamente, la palabra-razón no deja intacto al ser humano; el hombre es el ser que experimenta con cada pensamiento y cada palabra que se emite. Por su parte, la palabra no sólo vale por su contenido semántico que, por supuesto, se entiende; también es un elemento sonoro que puede ser explotado generando belleza en su pronunciación. La poesía, por ejemplo, casi siempre es una magnífica combinación entre sonido, significado y sentido. La palabra, entonces, es estética porque se siente, estremece al cuerpo, pero también se entiende con el logos.

La aísthesis es el complemento del logos, es decir, su símbolo. La pura racionalidad es incompleta. Por este motivo, la noción de una razón pura o formal no sería más que una estructura hueca. Pero a diferencia de lo que pensadores como Kant creían, la razón vacía de contenido parece inaccesible al hombre como también lo es la "sensación pura". En efecto, la conceptualización de la estructura formal racional es ya una experiencia del hombre que genera, cuando menos, perplejidad y ésta es una conmoción, o sea, una experiencia. En todo ejercicio racional, la aísthesis se encuentra "presente y activa", como diría Nicol. Por su parte, la palabra anestésica ${ }^{31}$ es irrepresentable porque su pronunciación supone ya el estímulo sensible y la subsecuente conmoción en uno mismo como receptor o alguien más que funja como tal. El logos no puede ser separado completamente de la aísthesis pero, como en toda relación simbólica, su vínculo es, a la vez, su distinción. Que el logos implique la aísthesis significa que son co-respondientes: cuando se presenta aquél, se activa ésta y viceversa. Por esta razón, la expresión del ser humano puede ser verbal o no verbal y, de todos modos, simbólica. Si lo que el hombre reconoce en el otro es la forma común de ser y ésta no es exclusivamente racional, sino que implica el logos y la aísthesis en comunión, entonces es claro que se reconocen estética y lógicamente: al sentir la presencia del otro se entiende que es un semejante; al entender que aquél es símbolo de uno mismo, se da la sensación de comunidad.

Nicol advierte que "la expresión es el ser en acto". ${ }^{32}$ El ser se manifiesta siempre en la acción humana, por un lado, y también actualiza lo que el hombre ha sido, por otro. Cada acción del hombre expresa su forma de ser que lo distingue de todos los demás entes. La expresión es lo que hace patente la comunidad del género humano; por ello, sólo el hombre es el ser de la expresión. Esto no quiere decir, desde luego, que los hombres expresen lo mismo; por el contrario, cada expresión es dialéctica porque al mismo tiempo individualiza a quien expresa, eso lo hace semejante a otro. De hecho, el filósofo catalán distingue al menos tres planos diferentes en cada expresión: 1) lo expresado

${ }^{31}$ Es decir, "sin aísthesis", incapaz de hacer sentir algo.

${ }^{32}$ E. Nicol, Metafísica de la expresión, p. 191. 
particularmente por un sujeto, 2) la particularidad de quien expresa, que se acentúa con la expresión misma y 3) la capacidad común a todos los hombres de expresar (expresividad). ${ }^{33}$ La expresión, entonces, diferencia y hace comunes a los hombres al mismo tiempo. La forma de ser del hombre, en tanto que ser de la expresión, es dialéctica.

Ahora bien, si como se ha afirmado líneas arriba, la expresión es el compuesto lógico-estético, entonces éstos también han de ser dialécticos. El logos es dialéctico porque toma y ofrece al ser en el mismo instante, ${ }^{34}$ es decir, en el individuo, la comprensión de lo real se da por medio de la racionalidad; en este sentido, el logos posibilita la comprensión de lo que se capta. Pero eso captado se puede comunicar a un semejante a través de la palabra. Lo que se ha obtenido se ofrece y tanto en lo primero como en lo segundo, el logos es el medio por el cual eso se lleva a cabo. La aísthesis hace prácticamente lo mismo, porque lo estético también capta al ser y lo ofrece: no puede haber expresión que no sea emitida y captada estéticamente; las experiencias se hacen presentes en el hombre por medio del sentir en general, esto quiere decir que siempre que haya una experiencia debe haber algún tipo de afección sensible. Y todo aquello que, a su vez, se ofrezca a alguien más, se emite estéticamente, es decir, generando un cierto sentir y, por consiguiente, también debe afectar sensitivamente al receptor de dicho ofrecimiento. Por lo tanto, la aísthesis opera de manera semejante al logos, pero no se identifica con él. De modo que la expresión es dialéctica en otro sentido, a saber, por la combinación del logos y la aísthesis. No es posible afectar con el puro logos; la palabra-razón no usa la aísthesis como un medio para actualizarse, en todo caso, el sentir se hace presente con el logos. Y puesto que no hay independencia del logos o de la aísthesis, resulta que siempre se hallan vinculados. Por ello, son símbolos el uno del otro.

Si, como se mencionó, cada expresión individualiza y muestra la comunidad ontológica del hombre, entonces también por ello se observa otra dinámica dialéctica del logos y la aísthesis. En efecto, cada expresión es distinta y, por ello, se individualiza el hombre. Lo que sucede es que cada expresividad es un logos articulado de forma peculiar e irrepetible: un pensamiento no puede ser reproducido de la misma manera por otro (ni por uno mismo) aunque sea comprensible para todos; una palabra no puede ser pronunciada igual por nadie, a pesar de que todo el mundo comprenda lo dicho. Otro tanto ocurre con la aísthesis, pues resulta claro que las experiencias no pueden ser compartidas de la misma manera y en la misma circunstancia ni con la misma

33 Cf. ibid., p. 195.

${ }^{34} C f$. E. Nicol, "fenomenología y dialéctica", en Ideas de vario linaje. México, UNAM, 1990, pp. 106-110. 
intensidad por dos hombres y, no obstante, son posibles los sentimientos de com-pasión o em-patía, que consisten en colocarse en las afecciones (y, por tanto, asemejar las sensaciones) de quien las padece. La aísthesis, igual que el logos, es dialéctica; la comunidad y la individualidad se hallan en ella.

Una vez más, se aprecia que el logos no puede presentarse absolutamente depurado. Su complemento, que posibilita la integridad del ser del hombre, es la aísthesis. Así, ideas como "animal racional" o "razón pura" son muy cuestionables porque atienden sólo a una parte (que no por ser tal es simple) del ser humano. Lo estético, entonces, no puede ser considerado ya como mera aprehensión sensible ni pura percepción; la aísthesis representa el complemento que el logos requiere para que el hombre se exprese. Si la razón está limitada, es porque ella sola no puede ser artífice de la expresividad y, por tanto, de la existencia del hombre. La vida humana se articula racional y estéticamente.

Con base en todo lo expuesto en el presente texto, puede apreciarse que lo estético, después de la revolución que ha llevado a cabo Eduardo Nicol, no puede reducirse a lo que Baumgarten llamó "la hermana menor de la lógica" 35 que, por ser contingente, debe ser superado y ordenado por la razón. Puede verse que el papel de la aísthesis es de capital relevancia para entender la forma de ser del ser de la expresión. Que el hombre sea expresivo implica que éste es esencialmente estético y lógico. Por supuesto, esto no pretende negar el papel de lo que se denominó estética calocéntrica; en todo caso, si la aísthesis es un componente ontológico (y por tanto esencial) del hombre, queda claro que la expresividad artística, que otorga mayor preponderancia a lo estético, es otra manera de ahondar en la realidad tan racional y rigurosa como lo es la ciencia y la filosofía. En todo caso, estas últimas diferirían de lo artístico en cuanto al objetivo y el método, pero no por su grado de racionalidad ni de sensibilidad: todo en el hombre es expresión, o sea, logos y aísthesis. Así, la historia y las formas simbólicas no son únicamente comprensibles sino empáticas en tanto estéticas. Tampoco se requiere asumir que lo estético es algo completamente ajeno al logos. Como se intentó mostrar, en cada manifestación humana la razón y lo estético se hallan implicados. La comprensión cabal de los fenómenos sería simplemente imposible si estos dos componentes fueran separados. Pero esto no significa que la importancia de lo sensible dependa del hecho de que proporcione datos al entendimiento; es decir, la aísthesis no es el medio por el cual el logos se activa y realiza sus funciones. Más precisamente, aísthesis y logos operan simultáneamente y aquélla no es la sierva de éste: las facultades humanas no tienen jerarquías. Sentir y pensar, esto es expresión; esto es el hombre.

${ }^{35}$ Citado en Raymond Bayer, Historia de la estética. Trad. de Jasmín Reuter. México, FCE, 1984, p. 184. 